\title{
Inferiority and Compensation in Palacio's Wonder
}

\author{
Nien-Hsin Hsieh ${ }^{1} \quad$ Ya-huei Wang ${ }^{1,2 *}$ \\ 1. Department of Applied Foreign Languages, Chung-Shan Medical University \\ 2.Department of Medical Education, Chung-Shan Medical University Hospital \\ No. 110, Sec. 1, Jian-Koa N. Rd, Taichung, Taiwan \\ E-mail: yhuei@csmu.edu.tw
}

\begin{abstract}
The study is based on the theory of Adler's inferiority complex and investigates how the influence of family and friendship can help children change their thinking when they encounter feelings of inferiority. Using the novel Wonder (2012), the study examines how the protagonist Auggie, suffering from Treacher Collins syndrome, after experiencing bullies and unfriendly treatment at school, manages to overcome his inferiority complex to adapt to his new school life and later reaches his individuation. Auggie must overcome his physical deformity, using positive compensation to reach his individual development and personal wholeness. By confronting his plight to manage his feelings of inferiority, Auggie develops concern for people, positively using compensation as a healthy desire to reach his goal for recognition and superiority.
\end{abstract}

Keywords: inferiority complex; individual psychology, compensation, individuation; personal wholeness

DOI: $10.7176 / J L L L / 55-03$

Publication date: April $30^{\text {th }} 2019$

\section{ORGAN INFERIORITY \& INFERIORITY COMPLEX}

Wonder (2012), a children's novel written by Raquel Jaramillo under the penname R. J. Palacio, describes how Auggie Pullman, a ten-year-old boy suffering from Treacher Collins syndrome, overcomes his inferiority complex to adapt to his new school life. Auggie lives in North River Heights in Upper Manhattan with his parents, his elder sister Olivia (Via), and a dog, Daisy. To remain alive, and avoid becoming blind or deaf, Auggie has had 27 surgeries since birth. Although the surgeries have kept Auggie alive, they also make his life totally different. Compared to normal kids' faces, Auggie's face looks different. As Via explains:

His [Auggie's] eyes are about an inch below where they should be on his face, almost to halfway down his cheeks. They slant downward at an extreme angle, almost like diagonal slits that someone cut into his face, and the left one is noticeably lower than the right one. They bulge outward because his eye cavities are too shallow to accommodate them (p. 67).

With no eyebrows and eyelashes, "scars around his [Auggie's] mouth," and a noticeable "jagged gash running from the middle of his upper lip to his nose" (p. 67), Auggie suggests that people might think he had been burned in a fire.

As a result, Auggie has been prone to organ inferiority and later develops an inferiority complex. Adler (2009), an Austrian medical doctor and psychotherapist, believes that if children lose their courage and feel frustrated about themselves, they might attempt to escape from the places or situations that make them feel depressed. When they encounter similar situations, they may feel ashamed of themselves instead of feeling better. Adler (2009) called this state an "inferiority complex." An inferiority complex makes people removed from the society, frustrated, and unconfident. People with inferiority complexes do not believe that they will advance in their lives (Davida \& Trandafiraa, 2011).

For instance, in Wonder, one day, Via invites her mother to watch a school play; however, her mother says she needs to care for Auggie at home. Via tries to explain that Auggie was not invited because the plot of the play might have been boring to a kid his age. Frustrated and depressed about his facial deformity, Auggie is convinced that he could not attend the play because of his face. Every time Auggie stands in crowds, he feels that he is the most "outstanding" person. People who whisper with their hands covering their mouths make him feel dejected and lack confidence. Similarly, Auggie thinks that his sister was ashamed of having such an "outstanding" brother. Auggie yelled at Via, saying "You think I don't know what's going on?"; "You just don't want your brand-new fancy high school friends to know your brother's a freak!" (p. 152).

In addition, as the school year begins, Julian Albans, a student the principal asks to help Auggie at school, bullies and humiliates Auggie. Auggie can also feel Julian "staring at me out of the corner of his eye. This is something I see people do a lot with me. They think I don't know they're staring" (p. 27). At a Halloween party, Julian says, in a laughing tone, "If I looked like that ... I swear to God, I'd put a hood over my face every day" (p. 60). Auggie cannot forget; he keeps reminding himself of his facial deformity.

How one adjusts one's feelings of inferiority to meet the demands of life determines one's subsequent success or failure in life (Lin, 1997). That is to say, though an inferiority complex is related to the feeling of inferiority to others in some way, when it is well managed, an inferiority complex may have polar effects. As 
Adler (2011) explains, people with inferiority complexes may have more difficulty reaching their goals.

Adler (2009) identifies three possible reasons for the development of an inferiority complex in early childhood: physically deformity, overindulgence, and neglect. Adler believes that it is difficult for children with physical deformities to reach self-fulfillment. Compared to others, people with inferiority complexes pay more attention to their physical malformations and hence tend to forget the people around them or the needy. People with inferiority complexes are used to focusing on themselves, on their malformations, dysfunctions, defects, or even weaknesses.

Children tend to feel helpless and spiritually rely on others to find the value in other people (Adler, 2009). When comparing themselves with others, people with feelings of inferiority or complexes may perceive their appearances as they really are and become depressed and frustrated. Adler (2009) declared that if no one helps these children divert attention from themselves to others or to outside world, these children might care only about their own feelings. Therefore, in order to overcome his inferiority complex, Auggie must divert his attention from himself to others and, further, keep a connection with the outside world.

\section{CAREGIVERS: AS A CONNECTION WITH SOCIAL RELATIONS}

People with disfigurements initially see differences between themselves and their family members (Sensky, 1985). Moreover, as Adler (1929) explains, to reach individuation, children should have connections not only with their family members but also with other social groups. When born weak, children need someone to take care of them (Adler, 1929). In a family, the primary caretaker has much power to act on his or her children during the process of raising them (Yamaoka, Tamiya, Izumida, Kawamura, Takahashi, \& Noguchi, 2016). Hence, how the primary caretaker interacts with his or her children is crucial for the children's individuation and personality development (Adler, 1929).

For example, the mother or family members who take care of the weakest children will somewhat influence the children's characteristics and feelings of inferiority, because the weakness might become someone's feelings of inferiority or complex in the future. Because children's initial social lives lie in their recognition of their individual weakness, if children feel that they belong to a certain social group, they may overcome maladjustment and inferiority complexes. On the contrary, if someone does not have relationships with others in a social group, that person might be unable to adjust or fight against his or her inferiority complex. Adler (2009) thus advocates that the primary caregiver plays an important role in children's personality development. The characteristics of caregivers and how they interact with children are crucial in helping children overcome their weaknesses and inferiority complexes. If children feel that they are in a hostile environment, they will not open their minds and make friends easily.

Because of his facial deformity, Auggie had been home-schooled. However, when he is going to be a fifthgrader, to help Auggie reach his individuality, Auggie's mother, saying, "We can't keep protecting him" (p. 14), decides to enroll Auggie in a private middle school (Beecher Prep) in Manhattan. This school will help Auggie make social connections with others and manage his inferiority complex. Auggie's mother says to her husband:

We can't just pretend he's going to wake up tomorrow and this isn't going to be his reality, because it is, Nate, and we have to help him learn to deal with it. We can't just keep avoiding situations that.... (p. 14)

Home is Auggie's refuge when he feels discouraged and frustrated. Auggie's family members support him. When Auggie is nervous on the first school day, Via comforts her brother, saying, "Everyone's just as nervous as you are ... . Just remember that this is everyone's first day of school. Okay?" (p. 33). Even the dog, Daisy, supported him: "My dog, Daisy, followed me into the room, jumped on the bed, and started licking me all over my face" (p. 31). With his family members' help, Auggie is ready for school, his first step into a social group.

However, it turns out that Auggie must endure taunting from his classmates and manage unfair treatment due to the difference of his face. Auggie can feel that "some kids were definitely staring at me . . . I did my thing of pretending not to notice" (p. 34). Although Auggie tries not to draw attention to his appearance, his efforts are in vain. He is humiliated in front of his classmates.

At the beginning of his school experience, Auggie is bullied and isolated by almost all of his school mates. Moreover, Halloween has been Auggie's favorite holiday; however, Auggie does not have fun at the party at school. At the school Halloween party, Auggie hears his best friend, Jack Will, laugh at Auggie's face behind his back with other classmates, Julian and Henry, who have always pushed around him. Feeling betrayed by his best friend, along with his interiority complex, Auggie experiences frustration and low self-esteem. According to Stagner (1961), frustration refers to a state of emotional stress, which may be expressed through annoyance and anger. Finally, Auggie starts crying:

And I started crying. I couldn't keep it from happening. The tears were so thick in my eyes I could barely see, but I couldn't wipe them through the mask as I walked. I was looking for a little tiny spot to disappear into. I wanted a hole I could fall inside of: a little black hole that would eat me up (p. 61). 
At home, Auggie is so angry that he punches his pillow, saying "I hate it! I hate it! I hate it!" (p. 82). Auggie's constant movement combined with strong temper reflects characteristics of those with feelings of inferiority (Adler, 1929). Moreover, Auggie feels betrayed by his friends, thinking that they may have been bribed by principal to be friends with him. His classmates' bullying makes Auggie feel humiliated, and he attributes the bullying and humiliation to his facial deformity.

Via tries to console Auggie, telling him that it is normal to have a bad day at school: "You have to go back to school. Everyone hates school sometimes. I hate school sometimes. I hate my friends sometimes. That's just life, Auggie" (p. 84). Via keeps persuading Auggie not to avoid but accept it as normal. She further encourages Auggie to fight against the hostile environment, telling him not to say a word to his friends:

August, actually, it's so cool that you know what they said, but they don't know you know what they said, you know?...You know what I mean. You don't have to talk to them ever again, if you don't want. And they'll never know why. See? Or you can pretend to be friends with them, but deep down inside you know you're not. (p.84)

With family support, Auggie manages to confidently have social contact. Although Auggie is willing to make friends with his schoolmates at first, after Halloween, he decides that no one really wants to be his friend, thinking that anyone who speaks in a friendly way to him was bribed by the teacher. His mom exhorts him to think positively; consequently, Auggie gets rid of his old thinking. Via also tries to help Auggie, saying, "Are you really going to let a couple of stupid kids keep you from going back to school? I know you've been enjoying it. Don't give them that power over you. Don't give them the satisfaction” (p. 84). If family members could not have given solace to Auggie, he might have imputed the reason for his best friend's betrayal to his own appearance and neglected that there might have been many reasons for the betrayal. Not only would it have been one sided for Auggie to put all the blame on one reason, but he also would have had a stronger tendency to side with his inferiority complex in the future. With his family's support, Auggie is willing to return to school to continue his individuation.

\section{INDIVIDUAL PSYCHOLOGY AND COMPENSATION}

Adler (1992) believes feelings of inferiority play a crucial role in children's personality development. He founded a school of psychology, individual psychology, based on the idea that human beings should be individual wholes and that they have the drive for compensation of inferiority feelings or complexes. Unlike Freud, who saw children's development through the lens of sexual stages, Adler believes that in order to reach individual wholeness, children must create social connections. Moreover, Adler (1992) thinks that only the coexistence of the conscious and the unconscious can represent a person's individual wholeness. Here the conscious and the unconscious are not contradictory to each other but a single unity. That is, a human being should be seen as a unity by considering both the conscious and the unconscious. Auggie may have a hard time at school. Nevertheless, he must face any situation bravely and positively, instead of burying his head in the sand. Adler (1992) argues that even if someone is fixated on taking a certain action, that person does not necessarily intend to take that action. For example, for a man who always unconsciously wants to jump out the window, actually jumping out the window is just one of the thoughts that releases pressure in his unconscious. It would be inappropriate to interpret that the man who wants to jump out the window is a timid man struggling with his desire for death. When focusing only one side, we may care only about the unconscious side, that is, the inferiority, and ignore the equal critical part, superiority. In individual psychology, consciousness and unconsciousness cannot be separated.

Although children can experience feelings of inferiority or complexes, Adler (1929) believes that people should accept their prototypes, which means what they should like themselves physically and mentally rather than try to change themselves into some ideal model. Those who are prone to challenges and surmount them will be more able to face the obstacles while pursuing superiority. Such children can also face their ego and competency needs can after coping with or compensating for their impaired appearances (Hill-Beuf \& Porter, 1984).

Inferiority complexes are inevitable in childhood. However, although they are weak and dependent on parents, children may use the mechanism of compensation to deal with their feelings of inferiority (Adler, 1992). Alder (2009) also suggested that there are two possible results for people with physical deformities. One is that they overcome their deformities and think that the deformities helped them advance in life. Another consequence is that their physical deformities become an obstacle for individuation. Auggie must overcome his physical deformity, using positive compensation to reach his individual development and personal wholeness.

\section{POSITIVE COMPENSATION VERSUS NEGATIVE COMPENSATION}

According to Adler (1992), people use compensation to attempt recognition or superiority. When people feel inferior or weak, they may try to compensate for their weakness or inferiority somewhere else. When positively used, compensation can be a healthy desire to motivate people to reach their goals of recognition and superiority. 
For instance, in Wonder, Auggie wishes that "every day could be Halloween" (p. 58). Auggie likes Halloween so much because on Halloween, he can dress in costume with a mask, and everyone looks the same with a mask. That is, with a mask, nobody sees Auggie's facial deformity. Auggie says:

I get to dress up in a costume. I get to wear a mask. I get to go around like every other kid with

a mask and nobody thinks I look weird. Nobody takes a second look. Nobody notices me.

Nobody knows me (p. 58).

In psychology, compensation is a connection with inferiority feelings. People with feelings of inferiority or complexes may, consciously or unconsciously, use compensation as a strategy to cover up their real or imagined weakness or physical inferiority. Hence, while managing well, children may use compensation to cover their deficiencies, incompetence, or frustrations in life while gratifying excellence in other areas (Cloninger, 2012). Therefore, using compensation, those with feelings of inferiority can overcome their difficulties. However, when used in the wrong way, compensation can be negative, that is, overcompensation and undercompensation. Overcompensation is when people have a superiority goal and strive for power or dominance. Undercompensation is characterized as having a need for help, and being fearful (Adler, 1917). Moreover, when used in a less positive way, people with inferiority complexes may also try to show their superiority over others, by bullying or dominating others (Adler, 2009).

Adler believes that everyone would figure out a strategy for living in order to cope with inferiority complexes, which Adler calls "life style" (Adler, 2009). At the Halloween party, Auggie enjoys wearing a masking and dressing in a costume because he can act out any role like any other kid, such as the role of astronaut, Peter Pan, or Captain Hook, and temporarily forget his facial deformity. For Auggie, dressing up at the Halloween party gives him have a release from his facial and organ inferiority, and in some ways, lets him seek superiority over others.

Some children may seek superiority by using illness to control others, because while ill, they receive much attention (Adler, 2009). Because Auggie is always sick and unable to attend school, he has been homeschooled by his mother. Auggie takes all of his parents' attention; as Via says, “August is the Sun. Me and Mom and Dad are planets orbiting the Sun. The rest of our family and friends are asteroids and comets floating around the planets orbiting the Sun" (p. 63). In one scene, Via's mother discovered that Via did not tell her that there is going to be a school play next week. Her mother is mad, saying, "But what is with you lately, Via? You're moody and taciturn and secretive...." Having been neglected all the time, Via fights back: "What is so wrong with my not telling you about a stupid play? . . I don't even have a speaking part in it!" (p. 151). Via complains that her parents neglect her all the time and pay attention only to Auggie, the one with Treacher Collins syndrome and a facial deformity. Thus, illness becomes a mechanism through which their parents pay more attention to Auggie, giving him have superiority over others. However, when Auggie discovers that Via is not going to invite him to the school play, Auggie feels hurt and neglected. He becomes angry and shouts at his mother and Via: "You're both liars! . . . You just don't want your brand-new fancy high school friends to know your brother's a freak!" (p. 152). Auggie then runs to his room, slamming his door violently, plopping onto his bed, and pulling the covers over himself. With his illness, Auggie knows that his temper tantrum will ensure that his mother pays attention to him and follows him into his room. Though small and weak, illness becomes a strategy for Auggie to get his parents to pay more attention to him and, somewhat, to control them.

However, Auggie's manipulation of his illness to control others does not work this time. His mother does not come to Auggie's bed because the dog is deathly ill. To reach individual development, Auggie, who used to be egotistic, has to learn to pay attention to those around him and become altruistic to others.

\section{SOCIAL INTEREST}

Social interest, which is always initially nurtured in the family, is an important concept in Adlerian psychology (Adler, 1956 \& 1964; Carlson \& Slavik, 1997). Social interest involves an interest in others and realizing their needs. Children with feelings of inferiority tend to lack social interest; they are self-interested (Adler, 1992). Being sick, Auggie has been egotistic. When their dog, Daisy, is dying, his mother pays attention to Daisy. When he fails to arouse attention from his mother, Auggie begins to bemoan his life span and what he has lost. Having been egotistic, Auggie cannot pay attention to his mother's feelings. When Via rushes to his room, saying, "Come quick. Mom needs to talk to you," Auggie refuses, saying "I'm not apologizing!" (p. 153). Via yells at Auggie: "Not everything in the world is about you, Auggie! Now hurry up. Daisy's sick. Mom's taking her to the emergency vet. Come say goodbye" (p. 153).

Via's statement proves a watershed in Auggie's life and lets Auggie begin to pay attention to others. At this moment, Auggie realizes the seriousness of Daisy's illness and empathizes with Via and his mother. Immediately pushing the pillow off of his face, Auggie follows Via's suggestion “[c]ome say goodbye” (p. 153). At this moment, Auggie begins to care about not only about his feelings but the feelings of others, saying that:

Daisy was lying down sideways on the floor with her legs straight out in front of her. She was panting a lot, like she'd been running in the park. Mom was kneeling beside her, stroking the 
top of her head (p. 153).

Only at this life-and-death turning point can Auggie pay attention to someone's feelings and become altruistic. When he sees Via "kneeling down next to Mom, ... who was crying too" (p. 153), Auggie begins to care about others and have a connection with others Seeing his mother trembling and the dog panting, Auggie becomes willing to admit his misconduct, care about others, and show his love to others. To console his mother, Auggie says, "I love you, Mommy!" (p. 155); "I'm sorry about what I said" (p. 157).

Because Auggie had been homeschooled his connection with the outside world was limited. Therefore, his development of social interest was hindered. To broaden Auggie's social connection, his parents send Auggie to middle school, which is Auggie's initial connection with social relations. Moreover, when he sees his dog dying, he can finally step out his feelings of inferiority, further extending his inner connection with others and expressing his empathy to others. Auggie thus successfully reaches a certain degree of social interest in others and individual wholeness.

\section{POSITIVE COMPENSATION FOR PERSONAL WHOLENESS}

Because they have been treated differently from normal children since they were infants, children with disfigurement are prone to feel humiliated when they are excluded by peers at the school (Bradbury, 2012). However, though small and weak, such children may discover a strategy to cope with their inferiority complexes, such as seeking artistic or intellectual achievement. Therefore, teachers play a critical role in comforting these children and triggering their potential ability. Adler (2009) believes that teachers should be at the school what mothers are at home. How should an educator help a student want to go to school? First, the teacher must pay attention to what students like. Then, the teacher should make the students believe that they can succeed, in order to increase their confidence. Fearful of postponing Auggie's study and losing social connection, his parents enroll him at school. When Auggie goes to school, the principal, Mr. Tushman, tells him that the science exam will be held at the school. Mr. Tushman uses what Auggie is interested in to entice Auggie to school. Mr. Tushman has confidence that Auggie will do well on the science exam.

Unfortunately, after starting school, his classmates make fun of Auggie's facial deformity and what Auggie looks like when he is eating, and are afraid of touching him and getting the "plague" (p. 88). Although Auggie is accustomed to people talking behind his back and staring at his face, he is still sad that no one wants to develop a friendship with him, and he lacks confidence at the beginning of his school life.

After experiencing bullies and unfriendly treatment at the school, Auggie gradually finds the value of himself in his favorite subject, science. Because Auggie is good at science, he can easily answer the questions and get good grades in class, which makes Auggie feel comfortable at school. It is the self-accomplishment that helps him forget about his facial deformity. At the end of the book, he gets first prize at the science fair with his best friend. As Mr. Tushman says, "He is the greatest" (p. 210). When walking across the stage, Mr. Tushman whispers to him, "Well done, Auggie" and places the gold medal over Auggie's head (p. 211). For Auggie, the accomplishment in science becomes a mechanism for positive compensation to reach recognition or superiority. Auggie has a feeling of floating on air. He says:

I felt like I was floating. It was so weird. Like the sun was shining full force on my face and the wind was blowing. As I got closer to the stage, I saw Ms. Rubin waving at me in the front row, and then next to her was Mrs. G, who was crying hysterically — a happy crying — smiling and clapping the whole time. And as I walked up the steps to the stage, the most amazing thing happened: everyone started standing up. Not just the front rows, but the whole audience suddenly got up on their feet, whooping, hollering, clapping like crazy. It was a standing ovation. For me (p. 211).

It would be short-sighted to interpret Auggie only as a timid boy who undergoes a hard time in order to let classmates get used to his face. Auggie certainly has a brave side. For example, he is willing to forgive the person who makes fun of his face and be friends with him again. Moreover, Auggie is good at science. Although he is betrayed by his close friends and is prone to feelings of inferiority, Auggie seeks intellectual achievement as compensation for the inferiority complex. He manages to struggle in the field with which he is fascinated on his school days and ultimately wins the science championship. As Adler (1992) mentions, to reach individual wholeness, human beings are inclined to have social connections and an urge to compensate for their inferiority complexes. Through his school life, August overcomes his inferiority complex and manages the school bullying.

Because a facial deformity is hard to hide, while getting along with his classmates, Auggie is self-conscious about his differences and feels frustrated and ashamed. In this period, the caring of his primary family caregivers, mainly his mother, has a great impact on stabilizing his unsteady emotions and enhancing the development of his psychology. With family support, Auggie can move along, endeavoring to accept his weakness; therefore, he finally finds his area of competence, with the assistance of his teachers.

How Auggie confronts his plight is the key to his individual development and personal wholeness. Although he experiences bullies and unfriendly treatment at school, Auggie overcomes his inferiority complex 
and adapts to his new school life. Gradually, he finds the value of himself in his favorite subject, science. Further, he builds a connection and empathizes with family members and schoolmates. Ultimately, he overcomes his feeling of inferiority and discovers what kind of person he is.

\section{REFERENCES}

Adler, A. (1917). Study of organ inferiority and its Psychical compensation: A contribution to clinical medicine (Monograph series, No.24). New York: Nervous and Mental Disease Publication.

Adler, A. (1929). Lebenskenntnis (8th ed). Frankfurt am Main: Fischer.

Adler, A. (1956). The Individual psychology of Alfred Adler: A systematic presentation of selection from his writings. New York: Basis Books.

Adler. A. (1964). Social interest: A challenge to mankind. New York: Capricorn Books.

Adler, A. (1992). Understanding human nature. Oxford: Oneworld.

Adler, A. (2009). What life could mean to you: The Psychology of personal development. Oxford, England: Oneworld Publications.

Alder, A. (2011). Science of living. CT, USA: Martino Fine Books.

Bradbury, E. (2012). Meeting the psychological needs of patients with facial disfigurement. British Journal of Oral and Maxillofacial Surgery, 50, 193-196.

Carlson, J., \& Slavik, S. (1997). Techniques in Adlerian psychology. New York: Taylor and Francis Group.

Cloninger, S. C. (2012). Theories of personality: Understanding persons. $6^{\text {th }}$ ed. Boston, MA: Pearson/Allyn and Bacon.

Davida, R., \& Trandafiraa, M. (2011). "I want to fly" - Initiating a program of psychological counseling in order to mitigate the inferiority complex of teenagers in disadvantaged families. Procedia: Social and Behavioral Sciences, 33, 533-537.

Hill-Beuf, A., \& Porter, J. D. R. (1984). Children coping with impaired appearance: Social and psychologic influences. General Hospital Psychiatry, 6,294-300.

Lin, T. (1997). Inferiority complex: Prevention in children and relief from it in adults. Biblical Studies Ministries International, 1-5.

Palacio, R. J. (2012). Wonder. New York: Knopf Books for Young Readers.

Sensky, T. (1985). Family stigma and physical deformity in children. General Hospital Psychiatry, 7(4), $385-$ 386.

Stagner, R (1961): Psychology of personality (3rd Edition) . New York: McGraw Hill

Yamaoka, Y., Tamiya, N., Izumida, N., Kawamura, A., Takahashi, H., Noguchi, H. (2016). The relationship between raising a child with a disability and the mental health of mothers compared to raising a child without disability in japan. SSM -Population Health, 2, 542-548. 